\title{
Excelling in Two Careers: A New Team Approach
}

\author{
Ben Humphrey \\ Parks College of Engineering and Aviation \\ Saint Louis University
}

\section{INTRODUCTION}

Dual career family situations have traditionally been approached with the assumption that both spouses have individual careers and must integrate them into their family situations. This paper presents the viewpoint that one spouse can successfully administer two different careers simultaneously, if the other spouse acts as organizer/augmenter to both careers (and the family.) Many situations exist which allow enough time for one spouse to take on two careers, but the burdens of scheduling, organization, and research, can stymie productivity. If that person is freed from basic or repetitious tasks and supported by not just an assistant, but a partner, a team can develop which produces superior results in both professions and in the home. In the University setting, with the flexibility of contact hours, research and service requirements, it is possible and reasonable under those suppositions to combine two careers, i.e. Professor/Minister.

\section{DIVISION OF EFFORTS-UNIVERSITY PROFESSORATE}

Because the wage-earning spouse bears responsibility to their employers, they necessarily assume general direction of the team. The "director" bases the structure of the partnership on the major requirements and/or expectations handed down by their superiors. They analyze obligations; sets priorities and chooses the specific route each project should take. They decide what actions and resources are needed to meet each goal and communicate those needs to the augmenter spouse. As conditions change, the director alters major and interim deadlines. Weighing the emphasis for individual projects or parts thereof falls mainly on the directing spouse, though input from the augmenting spouse helps balance the outlook.

Formal research needs are coordinated with the augmenter at all stages. The director tracks the progress and direction of major facets of each project. By receiving timely feedback they maintain a high degree of control over information. They avoid the tedium of overseeing minute details, which allows them time and energy for personal growth and creative endeavors. Though secretaries, research assistants and research partners do accomplish many of these functions in other cases, the family relationship of this team approach yields several benefits.

First, since the spouses already have many ideas and ideals in common, they tend to think along the same lines. Each partner knows what to expect from the other. Quality lines of communication already exist. Family bonds strengthen the desire and ability to understand each other's viewpoint.

Second, the augmenter appreciates the mindset, hidden expectations and otherwise unexpressed factors that motivate the director. This allows for candid communication, possibly inappropriate in a public setting.

Third, contact between partners is extended due to time spent together in normal family situations. Thoughts shared during casual conversation often lead to excellent solutions to 
problems encountered on the job. This is due to the atmosphere of openness and freedom of expression that exists among friends. Creative development blooms when freed from the stress found under regular working conditions.

Fourth, career and family responsibilities can be scheduled efficiently, saving time by combining errand trips and interspersing home chores as scheduled breaks in more sedentary or monotonous work. The close relationship permits organization of schedules with exceptional finesse. And, the "floating" spouse, freed from restraints imposed by an employer, can flex to accommodate the continual shifts in emphasis caused by the complications of two careers.

Fifth, much clerical and draft work can be accomplished efficiently by the augmenter, such as: posting of test results and assignments; placing of library reserve materials; production of transparencies; test booklets; and syllabi, etc. The time constraints placed on secretarial staff at the University level causes a reticence in professors to assign high volume, low-level processes to them. Instead of feeling the need to perform these basic tasks themselves, the director can assign them to the augmenter. This alleviates the stress of relying too heavily on outside help.

It is understood that the manager/augmenter spouse serves as an active partner. They bear responsibilities as significant as in a salaried position. This basic attitude is essential to maintain the discipline required for this coalition to work successfully. It is important for the augmenter to contribute their goals and ideas to the development and accomplishment the team's goals.

In the case of University professor/minister combination, it is obvious that gathering of information is vital. Complicated modern life demands diverse knowledge of countless subjects. A director can be swamped trying to stay on top of mounting trends and developments in their own disciplines, as well as in hundreds of other fields. The free-floating partner, though, can deftly navigate a vast sea of subjects. They then, organize and present news of current trends and state-of-the-art practices to the director for his information, using evenings, weekends, holidays and vacation times to generate bonus dialogue.

Hours of time can be devoted to searching databases, either from the home computer via the Internet, or through facilities at local and university libraries. The augmenter has the flexibility to travel freely, if needed, to pursue such resources. Copying, ordering and weeding through the basic material also falls to them.

The director receives the results of initial research. They cull inappropriate material, further refine the material, identify weak areas and assign follow-up. The augmenter continues to compile data and secure material. They organize revisions, type interim and final drafts, and participate in the editing process, including correcting grammar and spelling.

Many other small processes are assigned to the augmenter, such as: gathering resources for course-work upgrades; studying and processing information from memos; answering surveys; dealing with tax and retirement changes; keeping aware of university/church and community events, etc.

When the director is relieved of initial research and clerical duties they discover rich creative reserves within. They find time and mental energy to upgrade and enhance both careers. Together, the partners work to invent fresh approaches to teaching and to improve classroom and 
laboratory facilities. With help from the augmenter, the director can develop (and attend) seminars and workshops to expand and extend their ministries. They can intercept and assist students with scholastic needs.

While the augmenting spouse implements the goals, ideas, and opinions of the working spouse, they also blend their own unique vision into each endeavor. Each step of the process profits from the varied input of two minds. Frequent exchange widens the view and sharpens the focus. Ideas develop greater depth of field.

\section{DIVISION OF EFFORTS-CHURCH MINISTRY}

Due to the high cost of living, many small church congregations can no longer provide full-time salaries and/or living arrangements for their ministers. They must seek ministers who can combine their ministerial calling with other employment; for example, University professor. This bi-vocational arrangement allows churches to obtain the services of quality professional ministers without the burden of providing a full-time salary. This is one example of a second career that an individual might hold.

The minister/director must be aware of the needs of their congregation and its community. It becomes the job of the augmenter to search out and identify such needs. The minister/director concentrates their attention on hospital calls, other sicknesses or personal counseling and visitation necessities. They may assign the augmenter letters of greeting, encouragement or business to draft or process.

The director prepares and presents sermons and studies. They perform the ceremonies, rituals and functions of the church, serving as leader and host. They coordinate the goals and objectives of the congregation with church leaders and plan approaches and programs. In their capacity as denominational representative from a local congregation, the director needs background data for the preparation of reports, and presentations. They need to know what is taking place in the local church and community, as well as at the state and national levels of the church. This information is provided by the augmenter in forms most useful to the director.

The augmenter also serves as go-between and errand-runner for such things as deliveries, opening and closing buildings, and other behind-the-scenes duties to meet parishioners' needs. In small churches, many clerical duties fall to the minister. Preparation and distribution of weekly bulletins, newsletters, announcements, etc. can be relegated to the spouse. The spouse can also coordinate sermon subjects with worship themes, thus improving the quality of the worship experience. Even troubleshooting faulty equipment and making arrangements for repairs, can be coordinated by the augmenter. This frees the minister's mind of details and allows them to devote their attention and concern to people's needs.

Church work automatically involves both spouses in the work. It also intermingles voluntary service with that expected by the employer. This is also true of many service organizations, which might be the second career. 


\section{RELATIONSHIP ISSUES}

Effective communication and cooperation are the golden keys that gain access to the wealth of this partnership arrangement. Careful task assignment, division of labor and understanding of purposes is crucial. Many factors must be considered.

They are how to:

Discuss differing viewpoints positively

Work through disagreements

Deal with director/augmenter expectations

Separate work from play

Balance two employers' expectations

Share accomplishments

Develop lines of interaction and acceptance for augmenter with

director's superiors, peers, students and congregation

Divide home responsibilities

Deal with illnesses

Adapt to continually changing demands

\section{ADVANTAGES}

Provides greater flexibility in task selection and time management

Opens greater opportunities for research gathering

Uses individual strengths efficiently

Gains wider general acceptance of ideas by others

Broadens scope from differing experiences, education, expectations and gender

Puts united minds in "two places at once"

Encourages straightforward communication

Benefits from deeper intimacy and trust which exists between spouses

Affords small organizations access to quality direction and clerical staff

Allows closer household management

Makes possible caring for children or parents in the home

Enhances both careers by performing little "extras"

\section{DISADVANTAGES}

Demands a excellence in communication, cooperation and role acceptance

Needs careful management of time and loyalties

Calls for skillful goal structuring

Requires ability to balance between career obligations and between career and home life

Breaks with traditional approaches to careers and gender expectations

Possibly decreases total income, due to part-time secondary jobs

Defines augmenter as unemployed for resume and retirement purposes

Places the success of two careers and the family relationship on

the couple's strength of commitment, ability to

communicate, and respect for each others thoughts, despite their differences

Illness effects both careers 


\section{CONCLUSION}

This dual-career partnership could be applied to many different situations where one career allows flexible scheduling. It yields the satisfaction of knowing that the combination of efforts and thoughts has produced superior, far-reaching results. Differences in outlook, background and education diversify and enrich each project. The process of continual revision refines the product, making it more precise, more generally understandable, more likely to meet differing needs. Though challenging, this relationship exemplifies the venerable axiom, "The whole is greater than the sum of the parts."

BEN HUMPHREY is a professor in the Aerospace Engineering/Aircraft Maintenance Engineering Department of Parks College of Engineering and Aviation of Saint Louis University, where he has taught since 1985. He also has served as pastor to Missouri rural church congregations. He is presently serving as pastor at Shelbyville Baptist Church in Northeast Missouri. 